\title{
PREVALÊNCIA DAS INJÚRIAS TRAUMÁTICAS NA DENTIÇÃO DECÍDUA
}

\author{
TRAUMATIC INJURIES PREVALENCE IN PRIMARY DENTITION
}

\author{
Ana Claudia Ribas Cabral* \\ Danilo Antônio Duarte ** \\ Climene Valentim ***
}

\begin{abstract}
RESUMO
Introdução: As injúrias traumáticas na dentição decídua representam grande parte dos atendimentos de urgência na clínica de odontopediatria. Assim, é importante que o profissional esteja apto não só a diagnosticar, mas também a escolher a conduta terapêutica adequada pois, nesses casos, além das possíveis sequelas para o dente envolvido no acidente, existe a possibilidade de danos ao dente sucessor permanente. O objetivo desta pesquisa é estudar lesôes traumáticas em crianças na faixa etária de 7 a 72 meses, atendidas na Disciplina de Odontopediatria da Universidade Cidade de São Paulo (UNICID). Métodos: Foram analisados 232 prontuários, previamente preenchidos durante o atendimento clínico de urgência e acompanhamento clínico-radiográfico periódico, pela própria autora, no período de março de 1994 a junho de 2004. Resultados e Conclusão: Foram registrados 252 eventos traumáticos. Com base nos resultados obtidos neste estudo, foi possível concluir que as injúrias traumáticas ocorreram predominantemente no gênero masculino. A faixa etária de maior prevalência para este tipo de lesão foi a de 25 a 36 meses, sendo a luxação intrusiva a injúria traumática mais frequente. O incisivo central superior foi o dente decíduo mais envolvido nos eventos traumáticos, sendo queda a etiologia mais prevalente É importante salientar que medidas educativas e preventivas devem ser instituídas com o objetivo de reduzir numericamente os eventos traumáticos e minimizar as sequelas.
\end{abstract}

DESCRITORES: Prevalência • Dentição decídua • Traumatismos dentários

\section{ABSTRACT}

Introduction: Traumatic injuries in primary dentition represent a great part of the urgency attendances at pediatric dentistry clinics. Thus it's important that the dentist be apt not only to diagnosis but also to choose the adequate therapeutic behavior, because in these cases, in spite of possible future sequelae for the involved teeth in the accident, there is the possibility of damages to the follower permanent teeth. The objective of this research is to study the traumatic injuries to children between the ages from 7 to 72 months, who were examined at Pediatric Dentistry Department of the "Universidade Cidade de São Paulo (UNICID)". Methods: Were analysed 232 handbooks, previously filled during the clinical urgency attendance and periodic clinical-radiography accomplishment, by the author between March, 1994, to June, 2004. Results ande Conclusion: Were registred 252 traumatic events. According to the results in this study, it is possible to conclude that the traumatic injuries occured predominantly in the male genre. Bigger prevalence occurred the in ages from 25 to 36 months for this kind of injury, being the intrusive luxation the most frequent traumatic injury. The superior central incisor was the more involved deciduous tooth in the traumatic events, and occured predominantly at home, being falls the most frequent etiology.. It's important to point out that educative and preventive measures have to be implemented with the objective of reducing the traumatic events and to minimize future sequelaes.

DESCRIPTORS: Prevalence $\bullet$ Toot injuries $\bullet$ Dentition, primary

\footnotetext{
* Mestre em Odontopediatria pela Universidade Cruzeiro do Sul (UNICSUL) e professora assistente da Disciplina de Odontopediatria da Universidade Cidade de são Paulo (UNICID) e Universidade Metodista de São Paulo (UMESP.)

** Doutor em Odontopediatria pela Universidade de São Paulo (USP), professor titular da Disciplina de Odontopediatria da Universidade Cruzeiro do Sul (UNICSUL) e Universidade de Santo Amaro (UNISA)

*** Doutora em Odontopediatria pela Universidade de São Paulo (USP), professora titular da Disciplina de Odontopediatria da Universidade Cidade de são Paulo (UNICID) e Centro Universitário das Faculdades Metropolitanas Unidas (UNIFMU).
} 


\section{INTRODUÇÃO}

As injúrias traumáticas apresentam alta prevalência dentre as lesóes que afetam os tecidos bucais. Andreasen e Andreasen ${ }^{1}$ (1990) afirmam, que num futuro próximo ,os traumatismos excederão as doenças periodontais e a cárie representando, assim, uma ameaça significativa para a saúde bucal em pacientes jovens.

Os traumatismos dentoalveolares resultam de impactos cuja força agressora supera a resistência das estruturas dentárias, de suporte e da musculatura da regiâo envolvida, gerando danos físicos, estéticos e impactos psicológicos para o indivíduo envolvido nesse tipo de acidente.

Duas são as preocupaçóes dos pais perante as lesóes traumáticas em dentes decíduos: a estética e a possibilidade de danos ao dente sucessor permanente, o que se deve à íntima relação entre as dentições, representando um risco para o desenvolvimento do germe do sucessor, uma vez que o impacto no dente decíduo pode ser transmitido àquele no momento do acidente.

O Cirurgiáo-dentista deve atuar informando a população quanto às manobras preventivas com relação a esses tipos de lesões que afetam a cavidade bucal. É de grande importância que o profissional esteja habilitado para estabelecer o diagnóstico e a conduta terapêutica adequada para o caso, pois essas injúrias podem comprometer a qualidade de vida do indivíduo.

O estudo das prevalências das injúrias traumáticas na dentição decídua se torna relevante, pois permite ao profissional conhecer e interpretar aspectos desse tipo de lesão e, assim, a partir destes, estabelecer medidas preventivas e padronizar o atendimento de forma direcionada.

\section{REVISÃO DA LITERATURA}

No que se refere à prevalência de injúrias traumáticas na dentição decídua, diferentes estudos foram desenvolvidos nos últimos anos, sendo de grande importância para a análise desses resultados a avaliação da metodologia aplicada, que é a responsável pela variação nos resultados.

As injúrias traumáticas são frequentes na dentição decídua, apresentando prevalência de $15 \%$ a $71,4 \%$, em diferentes estudos, com crianças de diferentes faixas etárias.

Kenwood e Seow ${ }^{5}$ (1989), em estudo com crianças vítimas de traumatismo dentário, na faixa etária de 15 a 72 meses, observaram que $53,5 \%$ da amostra foram representados pelo gênero feminino, sendo a queda a etiologia responsável por $50,7 \%$ dos acidentes. Os incisivos superiores foram traumatizados em $95,3 \%$ dos casos, e a fratura coronária de esmalte e dentina foi a injúria traumática mais frequentemente observada $(11,6 \%)$, seguida de fratura de esmalte $(8,7 \%)$.

Llarena del Rosário et al. ${ }^{7}$ (1992) avaliaram crianças com traumatismo dentário, atendidas em âmbito hospitalar, na faixa etária de 6 meses a 7 anos e observaram que o pico de injúrias ocorreu na faixa etária de 2 a 3 anos $(34,6 \%)$, sendo que o gênero masculino apresentou maior número de traumas $(61,8 \%)$. As injúrias traumáticas observadas com maior frequência foram as lesões de tecidos moles $(37,5 \%)$, seguidas das luxaçóes $(26,8 \%)$ e avulsóes $(9,8 \%)$.

Osuji ${ }^{9}$ (1996) investigou a prevalência de injúrias traumáticas em crianças atendidas em âmbito hospitalar, na faixa etária de 1 a 7 anos, onde o gênero masculino apresentou maior prevalência de injúrias. $\mathrm{O}$ pico de lesóes ocorreu na faixa etária de quatro a cinco anos $(40,1 \%)$, estando o arco superior envolvido na maioria dos casos $(88,8 \%)$, sendo $67,6 \%$ representados pelos incisivos centrais. A injúria traumática mais frequente foi a subluxação $(58,3 \%)$, seguida da avulsão $(15,4 \%)$ e luxação intrusiva $(12,3 \%)$.

Wanderley ${ }^{13}$ (1999) avaliou crianças com traumatismo dentário na Faculdade de Odontologia da Universidade de São Paulo e observou que a faixa etária de maior prevalência desse tipo de injúria foi a de 3 a 5 anos (56\%), sem diferença significativa entre os gêneros masculino e feminino. A queda foi o fator etiológico observado com mais frequência (43,3\%). O arco superior estava envolvido em $95,4 \%$ dos acidentes, sendo o incisivo central o dente mais prevalente $(83,3 \%)$. A luxação foi a injúria traumática mais prevalente $(25,3 \%)$, seguida da fratura de esmalte $(17,6 \%)$, subluxação e avulsão $(12,4 \%)$.

Caldas e Burgos ${ }^{2}$ (2001) analisaram registros de pacientes atendidos em ambiente hospitalar em Recife, na faixa etária de $1 \mathrm{a} 5$ anos, e a prevalência de injúrias traumáticas foi de $30,8 \%$, com maior frequência no gênero masculino. A etiologia predominante foi a queda, sendo a luxação intrusiva a injúria mais representativa da amostra $(82,4 \%)$, estando os incisivos centrais superiores predominantemente envolvidos no acidente.

Saröglu e Sonmez ${ }^{11}$ (2002), com o propósito de avaliar o tipo de injúria traumática e sua prevalência nas dentições decídua e permanente, observaram 147 crianças atendidas em Universidade, na Turquia. Com relação à dentição decídua, foram avaliados 20 pacientes, totalizando 34 dentes. $\mathrm{O}$ gênero masculino representou $60 \%$ da amostra. A faixa etária de 4 anos apresentou 
maior prevalência de acidentes traumáticos (6 crianças). A queda foi a etiologia de $80 \%$ dos casos. Em 100\% da amostra as injúrias localizaram-se na maxila, sendo o incisivo central o dente mais frequentemente envolvido. A injúria traumática mais frequente neste estudo foi a luxação extrusiva $(38,25 \%)$, seguida da luxação intrusiva $(32,35 \%)$.

Porto et al..$^{10}$ (2003), com a finalidade de avaliar a prevalência de traumatismos alvéolo-dentários em crianças atendidas na Universidade Federal do Rio Grande do Sul, realizaram estudo através da análise de prontuários de crianças na faixa etária de 0 a 14 anos. $\mathrm{Na}$ dentição decídua foram encontrados 113 casos. O pico de acidentes na dentição decídua ocorreu na faixa etária de 2 a 4 anos. As injúrias mais prevalentes estavam relacionadas com os tecidos de sustentação, que representaram $79,64 \%$ dos casos, sendo que as injúrias de tecidos dentários duros representaram 20,36\% dos casos. A injúria mais frequente foi a luxação intrusiva $(28,32 \%)$, seguida da luxação lateral $(22,13 \%)$.

Scarpari et al. ${ }^{12}$ (2004) avaliaram prontuários de crianças na faixa etária de 0 a 48 meses, atendidas na Universidade Estadual de Campinas, com o objetivo de determinar a prevalência do traumatismo dentário. O gênero masculino representou $56 \%$ do grupo, sendo que a maior ocorrência de acidentes foi na faixa etária de 13 a 24 meses. A queda foi a maior causa de injúrias $(78 \%)$. Os incisivos centrais superiores foram mais frequentemente envolvidos neste estudo. No grupo de atendimento odontológico rotineiro, a injúria traumática mais prevalente foi a fratura de esmalte $(43 \%)$ e no grupo de atendimento de urgência foi a luxação (52\%), sendo $30 \%$ casos de luxação intrusiva.

Com o objetivo de estudar a prevalência de injúrias traumáticas na idade pré-escolar, Menezes et al. ${ }^{8}$ (2004) examinaram crianças na faixa etária de 0 - 5 anos, na cidade de Recife, Brasil. Foram observados traumatismos dentários em 436 crianças, representando uma prevalência de $32,6 \%$. Com relação ao gênero, o masculino foi mais envolvido em acidentes que o feminino $(60,77 \%$ e $39,22 \%$ respectivamente). A faixa etária com maior incidência de acidentes traumáticos foi a de 4 e 5 anos. As fraturas de esmalte representaram $53,4 \%$ dos casos, sendo os incisivos superiores os dentes envolvidos em $97,85 \%$ ( $43,1 \%$ o elemento 51 e $54,7 \%$ o elemento 61$)$ das crianças examinadas.

Ekanayake e Pereira $^{3}$, (2007), realizaram estudo em âmbito hospitalar e observaram que as injúrias traumá- ticas ocorreram predominantemente no gênero masculino, sendo que $95 \%$ dos dentes traumatizados eram incisivos centrais superiores e a injúria mais frequente foi a fratura de esmalte e dentina.

A presente pesquisa tem como objetivo estudar as injúrias traumáticas em crianças na faixa etária de 7 a 72 meses, atendidos na clínica de Odontopediatria da Universidade Cidade de São Paulo, no que se refere ao gênero, faixa etária, etiologia, dente e tipo de injúria traumática.

\section{MATERIAL E MÉTODOS:}

Material:

- Prontuário de atendimento da clínica da Disciplina de Odontopediatria da Universidade Cidade de São Paulo - UNICID

Métodos:

O presente estudo foi documental, com análise de 232 prontuários de atendimento de pacientes com injúria traumática na dentadura dentição, na Disciplina de Odontopediatria da Universidade Cidade de São Paulo - UNICID. Para a coleta de dados utilizou-se ficha especialmente desenvolvida para o estudo das injúrias traumáticas, com registro clínico e radiográfico.

A classificação das injúrias traumáticas na dentadura decídua utilizada foi a descrita por Andreasen e Andrea$\operatorname{sen}^{1}(2001)$.

Este estudo recebeu aprovação do Comitê de Ética para análise de projetos de pesquisas da Universidade Cruzeiro do Sul, protocolo no ${ }^{\circ}$ 010/07.

\section{RESULTADOS E DISCUSSÃO}

$\mathrm{O}$ atendimento neste estudo foi realizado, na maioria dos casos, imediatamente após o acidente. O curto espaço de tempo entre a injúria traumática e o atendimento permitiu que a coleta de dados fosse fundamentada em sinais clínicos e radiográficos da lesão e não só através de exame visual e relato dos responsáveis, permitindo assim, um diagnóstico mais preciso.

Dentre as 232 crianças, 139 pertenciam ao gênero masculino e 93 ao feminino, como mostra a Tabela 5.1, revelando uma maior prevalência para o gênero masculino $(59,9 \%)$.

Tal resultado vai ao encontro dos estudos epidemiológicos desenvolvidos nos últimos anos (Llarena Del Rosário et al. ${ }^{7}$ 1992, Osuji ${ }^{9}$ 1996, Saröglu e Sonmez ${ }^{11}$ 2002, Scarpari et al. ${ }^{12}$ 2004; Menezes et al. ${ }^{8}$ 2004; Ekanayake e Pereira ${ }^{3}$ 2007). A justificativa pode estar no fato 
Tabela 5.1: Distribuiçâo de crianças quanto à prevalência de traumatismo na dentiçáo decídua de acordo com o gênero:

\begin{tabular}{ccc}
\hline \hline Gênero & $\mathrm{n}$ & $\%$ \\
\hline Masculino & 139 & 59,9 \\
Feminino & 93 & 40,1 \\
Total de pacientes & 232 & 100 \\
\hline \hline
\end{tabular}

de os meninos apresentarem natureza mais agitada, com brincadeiras que oferecem maior perigo, sendo dada a eles uma liberdade maior para explorar o ambiente, enquanto que as meninas tendem a ser mais calmas, estimuladas a atividades delicadas. Contraditoriamente aos resultados aqui representados, Wanderley ${ }^{13}$ (1999), relata não haver diferença significativa entre os gêneros. Apenas o estudo de Kenwood e Seow ${ }^{5}$ (1988) descreve ser o gênero feminino o mais frequentemente envolvido em acidentes traumáticos na dentição decídua. Tais registros diferenciados, em relação ao gênero, podem ser atribuídos à proporção da população estudada, ou seja, uma diferença na distribuição de meninos e meninas na amostra inicial pode definir o resultado.

Observou-se neste grupo 252 eventos traumáticos, sendo que a faixa etária de maior ocorrência de lesôes traumáticas na dentição decídua, conforme demonstra a Tabela 5.2, foi de 25 a 36 meses (29,3\%), seguida da faixa de 12 a 24 meses (23\%). Para esse cálculo, foi considerada a idade da criança em cada evento traumático $(\mathrm{n}=252)$, pois uma mesma criança sofreu traumatismos em diferentes faixas etárias.

As divergências de prevalências com relação à faixa etária para acidentes traumáticos na dentição decídua, podem ser explicadas pelas diferenças na metodologia utilizada, tais como: faixa etária da população, critérios de inclusão da amostra e tipo de estudo. Os resultados obtidos nesta pesquisa vão ao encontro dos de Llarena Del Rosário et al. ${ }^{7}$ (1992), ressaltando-se que a faixa etária aqui estudada é similar à dos autores acima. Partindose da análise das faixas etárias dos estudos relatados na revista da literatura, pode-se afirmar que os resultados são comuns em estudos onde as amostras se assemelham. Alguns autores observaram uma maior ocorrência de traumatismos em faixas etárias mais avançadas, como de 4 a 5 anos (Osuji ${ }^{9}$ 1996, Menezes et al. ${ }^{8}$ 2004; GranvilleGarcia et al. ${ }^{4}$ 2006). Analisando as metodologias desses estudos, observa-se que são do tipo observacional, ou seja, com coleta de dados baseada apenas no exame clínico em creches e escolas, onde a idade registrada foi a do momento do exame e não a do acidente traumático, que poderia ter ocorrido em idades mais tenras. Kramer et al. ${ }^{6}$ (2003) acrescentam ainda que estudos observacionais apresentam maior frequência de injúrias em faixas etárias avançadas devido ao acúmulo de lesões dentárias com o decorrer dos anos, pois injúrias que não apresentem ou não desenvolvam sintomatologia náo recebem tratamento terapêutico, permanecendo o sinal clínico da lesão traumática até a esfoliação do dente decíduo ou manifestação de sintomatologia por alterações pulpares ou periodontais. A alta frequência de injúrias traumáticas em idades mais tenras pode ser justificada pelo fato do desenvolvimento motor ser imaturo, sem motricidade fina, não apresentando reflexo de proteção e defesa. Além do fato das crianças com pouca idade não possuírem consciência do perigo, aventurando-se involuntariamente na exploração do ambiente.

Os 252 acidentes resultaram em 396 dentes traumatizados, conforme relata a Tabela 5.3, sendo $41,8 \%$ representados pelo incisivo central superior direito (51)

Tabela 5.2: Distribuição de eventos traumáticos de acordo com a faixa etária

\begin{tabular}{|c|c|c|c|c|}
\hline Faixa Etária (meses) & Primeiro Evento traumático & Segundo Evento traumático & Terceiro Evento traumático & $\%$ \\
\hline & $\mathrm{n}$ & $\mathrm{n}$ & $\mathrm{n}$ & \\
\hline 7 a 12 & 12 & 0 & 0 & 4,7 \\
\hline 13 a 24 & 55 & 3 & 0 & 23 \\
\hline 25 a 36 & 67 & 7 & 0 & 29,3 \\
\hline 37 a 48 & 47 & 6 & 1 & 21,4 \\
\hline 49 a 60 & 33 & 2 & 0 & 13,8 \\
\hline 61 a 72 & 15 & 1 & 0 & 6,3 \\
\hline Não sabe* & 3 & 0 & 0 & 1,2 \\
\hline Total de Eventos traumáticos & 232 & 19 & 1 & 100 \\
\hline
\end{tabular}


Cabral ACR, Duarte DA, Valentim C. Prevalência das injúrias traumáticas na dentição decídua. Revista de Odontologia da Universidade Cidade de São Paulo 2009 mai-ago; 21(2): 137-43

e 40,6\% pelo incisivo central superior esquerdo (61), demonstrando que $82,4 \%$ dos dentes acometidos por trauma eram incisivos centrais superiores, resultado este advogado por Kenwood e Seow ${ }^{5}$ (1989), Osuji ${ }^{9}$ (1996), Wanderley $^{13}$ (1999), Saröglu e Sonmez ${ }^{11}$ (2002), Scarpari et al. ${ }^{12}$ (2004), Menezes et al. ${ }^{8}$ (2004), Ekanayake e Pereira ${ }^{3}$ (2007). Observou-se que 97,2\% dos dentes localizaram-se no arco superior, resultado compartilhado com a maioria dos autores (Kenwood e Seow ${ }^{5}$ 1988, Llarena Del Rosário et al. ${ }^{7}$ 1992, Osuji ${ }^{9} 1996$, Wanderley ${ }^{13}$ 1999, Saröglu e Sonmez ${ }^{11}$ 2002, Scarpari et al. ${ }^{12} 2004$ ). A justificativa relaciona-se à posição vulnerável no arco superior, pois fisiologicamente a maxila se projeta sobre a mandíbula, conferindo proteção à mesma. Deve-se considerar que a maxila é fixa no esqueleto, recebendo com maior intensidade o impacto do que a mandíbula, que por ser móvel tende a receber uma força com menor intensidade. Outro aspecto a ser considerado relaciona-se ao trabeculado ósseo mais frouxo da maxila, com tábua óssea mais fina, menos compacta que a mandíbula. A maior susceptibilidade desse arco pode se agravar com a presença de hábitos indesejáveis de sucção não nutritiva e respiração oral na fase de dentiçáo decídua, levando a alteraçấo na oclusão dos dentes anteriores, resultando na vestibularização desses dentes e consequentemente a ausência de vedamento labial, tornando assim os dentes ântero-superiores mais susceptíveis aos acidentes traumáticos devido à ausência de proteção pelo lábio superior.

Com relação à etiologia das lesôes traumáticas, a queda mostrou-se predominante (Tabela $5.4-67,9 \%$ ), seguida do choque com objeto imóvel (21,8\%).

Tal resultado é também referenciado por diversos autores (Kenwood e Seow5 1989, Osuji 1996 , Wanderley ${ }^{13}$ 1999, Saröglu e Sonmez ${ }^{11}$ 2002; Scarpari et al. ${ }^{12}$ 2004;). Essa unanimidade com relação à predominância das quedas pode ser justificada não só pela imaturidade motora e falta de consciência dos perigos nas crianças em idades mais tenras, mas também pelo ambiente em que elas se encontram, ou seja, presença de tapetes escorregadios, pisos lisos, o uso de produtos de limpeza inadequados, sapatos deslizantes, presença de móveis próximos a janelas e ausência de proteção em lajes. Uma atenção com esses detalhes poderia resultar na diminuição dos acidentes traumáticos.

A discussão da prevalência do tipo de injúria traumática mais incidente na dentição decídua deve ser criteriosa, pois é dependente de alguns fatores, como, exame proposto na metodologia, tipo de estudo, classificação
Tabela 5.3: Distribuiçâo dos dentes decíduos envolvidos nos eventos traumáticos:

\begin{tabular}{ccc}
\hline \hline $\begin{array}{c}\text { Dente envolvido no acidente } \\
\text { traumático }\end{array}$ & $\mathrm{n}$ & $\%$ \\
\hline 51 & 166 & 41,8 \\
52 & 22 & 5,5 \\
53 & 3 & 0,8 \\
54 & 1 & 0,3 \\
55 & 1 & 0,3 \\
61 & 161 & 40,6 \\
62 & 30 & 7,5 \\
63 & 1 & 0,3 \\
71 & 4 & 1 \\
72 & 1 & 0,3 \\
74 & 1 & 0,3 \\
81 & 3 & 0,8 \\
82 & 2 & 0,5 \\
Total & 396 & 100 \\
\hline
\end{tabular}

Tabela 5.4: Distribuição dos eventos traumáticos de acordo com a etiologia:

\begin{tabular}{ccc}
\hline \hline Etiologia & $\mathrm{n}$ & $\%$ \\
\hline Queda & 171 & 67,9 \\
Choque objeto imóvel & 55 & 21,8 \\
Choque objeto móvel & 16 & 6,3 \\
Desconhecido & 10 & 4 \\
Total de eventos traumáticos & 252 & 100 \\
\hline \hline
\end{tabular}

utilizada, local onde foi realizada, população examinada e intervalo de tempo entre o acidente e o atendimento clínico ou registro do traumatismo.

Com relação ao tipo de exame, fica evidente que a utilização da imagem radiográfica complementando o clínico permite um diagnóstico mais preciso, pois para algumas injúrias traumáticas a imagem radiográfica é diferencial para o diagnóstico da lesão traumática do paciente. Estudos do tipo observacionais, que utilizam apenas o exame visual, podem ou náo lançar mão de questionários, detalhe que seguramente apresentaria diferentes resultados, pois fornecem maior riqueza de dados do acidente. A classificação pode também gerar divergências com relação à prevalência de determinadas lesões, pois existem distinçôes conceituais nas classificações desenvolvidas pelos autores. Pesquisas desenvolvidas em hospitais ou centros de urgência odontológica 
Cabral ACR, Duarte DA, Valentim C. Prevalência das injúrias traumáticas na dentição decídua. Revista de Odontologia da Universidade Cidade de São Paulo 2009 mai-ago; 21(2): 137-43

revelam uma maior prevalência de injúrias traumáticas mais severas, com sinais clínicos evidentes, que despertam no responsável a consciência da necessidade de um atendimento especializado e imediato. Por outro lado, estudos desenvolvidos em consultórios, creches, escolas ou clínicas de universidades, tendem a registrar injúrias menos severas ou até mesmo diagnosticadas através das sequelas presentes. $\mathrm{O}$ período decorrido entre o acidente e o atendimento ou coleta de dados do traumatismo deve interferir na prevalência, pois exames realizados em curto espaço de tempo após o acidente permitem um diagnóstico mais preciso baseado na avaliação clínica.

Analisando o tipo de tecido envolvido no acidente traumático, a Tabela 5.5 demonstra que neste estudo $71,3 \%$ das lesões envolveram os tecidos de sustentação do elemento dentário, resultado semelhante ao de Porto et al. ${ }^{10}$ (2003).

Tabela 5.5 Distribuição dos eventos traumáticos de acordo com o tipo de tecido envolvido.

\begin{tabular}{ccc}
\hline \hline Lesão traumática & $\mathrm{n}$ & $\%$ \\
\hline $\begin{array}{c}\text { Lesôes traumáticas nos tecidos } \\
\text { dentários }\end{array}$ & 123 & 28,7 \\
$\begin{array}{c}\text { Lesōes traumáticas nos tecidos de } \\
\text { sustentação }\end{array}$ & 305 & 71,3 \\
$\quad$\begin{tabular}{c} 
Total de injúrias traumáticas \\
\hline
\end{tabular} & 428 & 100 \\
\hline
\end{tabular}

A Tabela 5.6 expressa que a injúria traumática de maior prevalência nesta pesquisa foi a luxação intrusiva $(16,9 \%)$, seguida da avulsão $(15,6 \%)$ e fratura de esmalte $(10,5 \%)$.

Estudos realizados por Porto et al. ${ }^{10}$ (2003) e Scarpari et al. ${ }^{12}$ (2004) são unânimes quanto à maior prevalência da luxação intrusiva na dentição decídua. Analisandose as metodologias desses estudos, pôde-se observar semelhança com a nossa pesquisa, ou seja, são resultantes de análise de prontuários de atendimento de urgência do traumatismo dentário, sendo o de Caldas e Burgos ${ }^{2}$ (2001), realizado em hospital e os de Porto et al. ${ }^{10}$ (2003) e Scarpari et al. ${ }^{12}$ (2004) em Universidade. Observam-se que injúrias do tipo luxação representaram o grupo de maior prevalência $(31,5 \%)$, à semelhança de Wanderley $^{13}$ (1999) e Saröglu e Sonmez ${ }^{11}$ (2002). Tal semelhança é possível de ser comparado a este estudo, pois foram realizados em universidades, em atendimentos especializados, com utilização de exames clinico e radiográfico. A justificativa para a alta prevalência de luxaçôes na dentição decídua pode ser creditada ao osso alveolar menos re-
Tabela 5.6: Distribuiçâo percentual dos eventos traumáticos na dentiçâo decídua.

\begin{tabular}{ccc}
\hline \hline Tipo de injúria traumática & $\mathrm{n}$ & $\%$ \\
\hline Fratura de esmalte & 44 & 10,5 \\
Fratura de esmalte e dentina & 38 & 8,9 \\
Fratura de esmalte e dentina com & 1 & 0,2 \\
exposição pulpar & 30 & 7 \\
Fratura Coronorradicular & 10 & 2,3 \\
Fratura Radicular & 19 & 4,4 \\
Laceração de tecidos moles & 34 & 7,9 \\
Concussão & 50 & 11,7 \\
Subluxação & 13 & 3 \\
Luxação lateral Vestibular & 26 & 6 \\
Luxação lateral Palatina & 2 & 0,5 \\
Luxação lateral Mesial & 72 & 16,9 \\
Luxação Intrusiva & 22 & 5,1 \\
Luxação Extrusiva & 67 & 15,6 \\
Avulsão & 428 & 100 \\
Total de injúrias & & \\
\hline \hline
\end{tabular}

siliente, com trabeculado frouxo, conferindo uma maior elasticidade a esse tecido, impedindo que ele resista à força e acompanhe a direção do impacto, resultando no deslocamento (luxação) do elemento dentário. A avulsão, como mostra a Tabela 5.6, representou a segunda injúria traumática mais prevalente na dentição decídua, resultado observado no relato de Osuji ${ }^{8}$ (1996). Em uma análise detalhada dos estudos da revisão da literatura, foi possivel agrupar os estudos observacionais e destacar que a maior parte deles obteve fraturas coronárias como injúrias mais prevalentes (Yagot et al. ${ }^{14} 1988$, Menezes et al. ${ }^{8}$ 2004). Isso se deve ao fato de que esses estudos realizam apenas o exame visual, detectando sequelas de traumatismos que não foram reabilitadas, muito provavelmente por não apresentarem sintomatologia, não despertando assim no responsável a necessidade de tratamento.

\section{CONCLUSÕES:}

1) As injúrias traumáticas foram mais prevalentes no gênero masculino.

2) A faixa etária de 25 a 36 meses foi a mais frequentemente envolvida nos eventos traumáticos.

3) A luxação intrusiva foi a injúria traumática predominante.

4) $\mathrm{O}$ dente mais frequentemente envolvido nas injú- 
rias traumáticas foi o incisivo central superior.

5) A queda representou a etiologia predominante nos eventos traumáticos.

6) Medidas preventivas devem tomadas com o objetivo de diminuir a susceptibilidade das lesóes traumáticas na dentição decídua, evitando-se assim, o estabelecimento de sequelas para a própria dentição decídua e possíveis repercussóes para a permanente.

\section{REFERÊNCIAS}

1. Andreasen JO, Andreasen FM. Dental Traumatology: quo vadis. Endod Dent Traumatol 1990 Apr; 15(6): 78-80.

2. Caldas AF, Burgos ME. A retrospective study of traumatic dental injuries in a Brasilian dental trauma clinic. Dent Traumatol 2001 Dec; 17(6): 250-3.

3. Ekanayake L, Pereira M. Pattern of traumatic dental injuries in children attending the University Dental Hospital, Sri Lank . Dental Traumatol 2008 Aug; 24(4): 471-4.

4. Granville-Garcia AF, de Menezes VA, de Lira PI. Dental trauma and associated factors in Brazilian preschoolers. Dent Traumatol 2006 Dec; 22(6): 31822.

5. Kenwood M, Seow WK. Sequelae of trauma to the primary dentition. J Pedod 1989; 13(3): 230-8.

6. Kramer PF, Zembruski C, Ferreira SH, Feldens CA. Traumatic dental injuries in Brazilian preschool children. Dent Traumatol 2003 Dec; 19(6): 299-303.

7. Llarena del Rosário ME, Acosta Alfaro VM, Garcia-Godoy F. Traumatic injuries to primary teeth in México City children. Endod Dent Traumatol 1992 Oct; 8(5): 213-214.

8. Menezes VA, Granville-Garcia AF, Santos K, Diamorim ME. Prevalência de traumatismo dentário em pré-escolares da rede pública municipal da cidade do Recife. Rev Odonto Ciênc 2004 jul-set; 19(45): $245-49$.
9. Osuji OO. Traumatised primary teeth in Nigerian children attending University hospital: the consequences of delays in seeking treatment. Int Dent $J$ 1996 jun; 46(3): 165-70.

10. Porto BR, Freitas JSA, Cruz MRS, Bressani AEL, Barata JS, Araújo FB. Prevalência de traumatismos alvéolo-dentários na clínica de urgência odontopediátrica de FO.UFRGS. Rev Fac. Odontol Porto Alegre 2003 jul; 44(1): 52-6.

11. Saroglu I, Sönmez H. The prevalence of traumatic injuries treated in the pedodontic clinic of Ankara University, Turkey, during 18 months. Dent Traumatol 2002 Dec; 18(6): 299-303.

12. Scarpari CEO, Possobon RF, Moraes ABA. Ocorrência de traumatismos em dentes decíduos de crianças atendidas no Cepae - FOP- UNICAMP. JBP Rev Ibero-am Odontopediatr Odontol Bebê 2004 janfev: 7(35): 33-40.

13. Wanderley MT. Casuística do atendimento no Centro de Pesquisa de Traumatismo na dentição decídua da Disciplina de Odontopediatria da FOUSP, em São Paulo. [Mestrado] São Paulo: Faculdade de Odontologia da USP; 1999.

14. Yagot KH, Nazhat NY, Kuder SA. Traumatic dental injuries in nursey schoolchildren from Baghdad, Iraq. Community Dent Oral Epidemiol 1988 Oct; 16(5): 292-3.

Recebido em: 25/11/2008

Aceito em: 1/06/2009 